\title{
A RETROSPECTIVE DEFERRAL ANALYSIS OF BLOOD DONORS IN A TERTIARY CARE MEDICAL COLLEGE BLOOD BANK UNIT- AN EXPERIENCE FROM RURAL KONKAN OF WESTERN MAHARASHTRA
}

\author{
Anand Ashok Bhosale1, Alvi Mehandi Rais Rukhsar², Vijay Dombale3, Narendra Shriram Madhekar, Maruti B. Desai ${ }^{5}$ \\ 1 Professor, Department of Pathology, BKL Walawalkar Rural Medical College, Kasarwadi, Ratnagiri, Maharashtra. \\ 2DMLT Student, Department of Pathology, BKL Walawalkar Rural Medical College, Kasarwadi, Ratnagiri, Maharashtra. \\ 3Professor, Department of Pathology, BKL Walawalkar Rural Medical College, Kasarwadi, Ratnagiri, Maharashtra. \\ ${ }^{4}$ Professor, Department of Preventive and Social Medicine, BKL Walawalkar Rural Medical College, Kasarwadi, Ratnagiri, \\ Maharashtra. \\ 5Statistician, BKL Walawalkar Rural Medical College, Kasarwadi, Ratnagiri, Maharashtra.
}

\begin{tabular}{l}
\hline ABSTRACT \\
BACKGROUND \\
Blood transfusion safety begins with healthy donors. Blood donors are deferred for multiple reasons and are not able to donate blood \\
successfully, either permanently or temporarily. The aim of this study is to study the main causes of pre-donation deferral of \\
potentially healthy prospective blood donors in a Tertiary care teaching hospital, Blood Bank unit.
\end{tabular}

\section{MATERIALS AND METHODS}

A retrospective analysis of records of the donors from January 2012 to December 2016 at Swami Samarth Blood Bank attached to BKL Walawalkar Rural Medical College, Sawarde, Chiplun Taluka, Ratnagiri Dist. in order to find out the rate and causes of deferral in pre-donation period both in male and female donors.

\section{RESULTS}

Study showed that the deferral rate was $4.37 \%$. Donors are deferred for multiple reasons. The temporary causes of deferral were more as compared to the permanent causes found to be statistically highly significant. Anaemia was the most common reason $(31.30 \%)$ in temporary deferrals, while Hypertension (78.35\%) is the most common reason in permanent deferral. Most of these deferral donors were (56.25\%) females and (44.45\%) males were of age 18 - 30 years old. Among male deferrals, hypertension constituted as a cause in $46.43 \%$ followed by other diseases and Anaemia, i.e. $22.77 \%$ and $14.73 \%$ respectively. While Anaemia $(86.27 \%)$ and hypotension $(9.8 \%)$ were the causes of choice in females.

\section{CONCLUSION}

The blood transfusion services should develop strategies to identify and rationalise the donor selection criteria and be able to decrease unnecessary deferrals.

\section{KEYWORDS}

Blood Donor, Deferral, Permanent, Temporary.

HOW TO CITE THIS ARTICLE: Bhosale AA, Rukhsar AMR, Dombale V, et al. A retrospective deferral analysis of blood donors in a tertiary care medical college blood bank unit- an experience from rural Konkan of Western Maharashtra. J. Evolution Med. Dent. Sci. 2017;6(95):7040-7043, DOI: 10.14260/jemds/2017/1527

\section{BACKGROUND}

Blood donors are deferred for various reasons. Moreover, deferring prospective donors often leaves them with negative feelings about themselves as well as the blood donation process.(1) Deferral leads to loss of precious whole blood donors (WBD) and blood units available for transfusion purposes.(2) By developing strategies to identify and rationalise donor selection criteria, the blood transfusion services should be able to decrease unnecessary deferrals. ${ }^{3}$ ) The few studies done in India in the past have provided different common reasons for deferral of blood donors, highlighting differing demographic profile in different parts of the country. (4)

'Financial or Other Competing Interest': None.

Submission 08-11-2017, Peer Review 05-12-2017,

Acceptance 11-12-2017, Published 23-12-2017.

Corresponding Author:

Dr. Anand Ashok Bhosale,

BKL Walawalkar Rural Medical College,

Kasarwadi, Sawarde, Taluka-Chiplun,

District Ratnagiri-415606, Maharashtra.

E-mail: anandbhosale2007@gmail.com

DOI: $10.14260 /$ jemds $/ 2017 / 1527$

\section{(c) (1) $($ )}

The present study was undertaken to analyse the predonation deferral incidence and pattern among blood donors.

\section{MATERIALS AND METHODS}

This retrospective descriptive study record based analysis was carried out for whole blood donors at Blood Bank over a period of 5 years from January 2012 to December 2016 at Swami Samarth Blood Bank attached to BKL Walawalkar Rural Medical College, Sawarde, Chiplun Taluk, Ratnagiri Dist. Donors who have donated blood at our outdoor voluntary blood donation camps as well as at our blood bank (indoor) were included in the study. Standard operating procedures based on the Directorate General of Health Services Guidelines, Ministry of Health and Family Welfare (2003) were used for donor selection and deferral. Pre-donation screening tests like donor questionnaire followed by physical examination and $\mathrm{Hb}$ estimation by $\mathrm{CuSO}_{4}$ (finger prick) method with cut-off value of $12.5 \mathrm{gm} / \mathrm{dL}$ were done. Donors with systolic BP between 100 and $180 \mathrm{mmHg}$ and diastolic BP between 50 and $100 \mathrm{mmHg}$ were accepted for blood donation. First time and repeat donors were not segregated and for the sake of simplicity of analysis, all repeat presentations were considered as independent attempts for blood donation. 
Detailed information on the donor deferral including the cause of deferral was recorded in deferral register. Completeness of data assured prior collection. Deferred donor data was analysed with respect to age, sex and causes of deferral (temporary and permanent). Suitable statistical tests were applied to find significant differences among variables.

\section{RESULTS}

\begin{tabular}{|c|c|c|c|c|}
\hline Sr. No. & Donors & Male & Female & Total \\
\hline 1 & Selected & 7950 & 354 & $\begin{array}{c}8304 \\
(95.63 \%)\end{array}$ \\
\hline 2 & Rejected & $\begin{array}{c}316 \\
(3.82 \%)\end{array}$ & $\begin{array}{c}64 \\
(15.31 \%)\end{array}$ & $\begin{array}{c}380 \\
(4.37 \%)\end{array}$ \\
\hline \multicolumn{4}{|c|}{ Table 1. Distribution of Registered, Selected } \\
and Rejected Donors \\
\hline
\end{tabular}

Overall, rejection rate was found to be $4.37 \%$. More in females compared with males, i.e. $15.31 \%$ and $3.82 \%$ respectively.

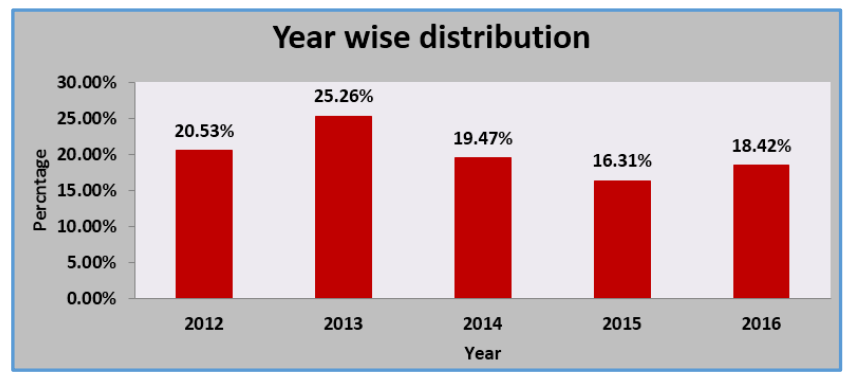

Figure 1. Year Wise Distribution of Blood Donors

Year wise deferral did not show significant differences in rate.

\begin{tabular}{|c|c|c|c|}
\hline Sr. No. & Age in Years & No. Male (\%) & No. Female (\%) \\
\hline 1 & $<18$ & $19(6.12)$ & $03(4.68)$ \\
\hline 2 & $18-30$ & $141(44.45)$ & $36(56.25)$ \\
\hline 3 & $30-40$ & $81(25.64)$ & $15(23.45)$ \\
\hline 4 & $40-50$ & $58(18.36)$ & $06(9.37)$ \\
\hline 5 & $50-60$ & $16(5.07)$ & $03(4.69)$ \\
\hline 6 & $>60$ & $01(0.36)$ & $01(1.56)$ \\
\hline \multicolumn{3}{|c|}{ Table 2. Age and Sex Wise Distribution of Deferral } \\
Respondents \\
\hline
\end{tabular}

Age is taken in completed years.

Majority of deferrals were in age range of 18 to 30 followed by 30 to 40 in both males and females.

\begin{tabular}{|c|c|c|}
\hline Deferrals & No. of Cases & Percentage \\
\hline Temporary & 246 & $64.73 \%$ \\
\hline Permanent & 134 & $35.26 \%$ \\
\hline Total & $\mathbf{3 8 0}$ & $\mathbf{1 0 0} \%$ \\
\hline \multicolumn{2}{|c|}{ Table 3. Types of Deferrals } \\
\hline
\end{tabular}

$\mathrm{X}^{2}=33$, d.f. $=1, \mathrm{P}<0.001$ H.S.

Rejection on the basis of cause was found to be in an approximate ratio of 2: 1 for temporary and permanent was found to be statistically highly significant.

\begin{tabular}{|c|c|c|c|}
\hline Sr. No. & Causes & No. of Cases & \% \\
\hline 1 & Anaemia & 77 & 31.30 \\
\hline 2 & Alcohol & 24 & 9.75 \\
\hline 3 & Medication & 20 & 8.13 \\
\hline 4 & Low Wt. & 17 & 6.91 \\
\hline 5 & Low Age & 16 & 6.50 \\
\hline 6 & Inadequate Sleep & 15 & 6.09 \\
\hline 7 & Jaundice & 13 & 5.28 \\
\hline 8 & Tuberculosis & 11 & 4.47 \\
\hline 9 & Vaccination & 8 & 3.25 \\
\hline 10 & Malaria & 7 & 2.84 \\
\hline 11 & Fever & 6 & 2.43 \\
\hline 12 & Typhoid & 5 & 2.03 \\
\hline 13 & Loose Motion & 4 & 1.62 \\
\hline 14 & Previous Blood Donation & 3 & 1.21 \\
\hline 15 & Menses & 3 & 1.21 \\
\hline 16 & Surgery & 3 & 1.21 \\
\hline 17 & Dog Bite & 3 & 1.21 \\
\hline 18 & Pulse Rate & 2 & 0.81 \\
\hline 19 & Chicken Pox & 2 & 0.81 \\
\hline 20 & Piles & 2 & 0.81 \\
\hline 21 & Dental Pain & 2 & 0.81 \\
\hline 22 & Headache & 1 & 0.40 \\
\hline 23 & Venepuncture Problem & 1 & 0.40 \\
\hline 24 & Sweating at Night & 1 & 0.40 \\
\hline \multicolumn{3}{|c|}{ Table 4A. Temporary Deferral } \\
\hline
\end{tabular}

\section{Multiple Responses}

Almost $1 / 3^{\text {rd }}$, i.e. $31.30 \%$ revealed low haemoglobin level as a cause of temporary rejection followed by alcohol $(9.75 \%)$, medication $(8.13 \%)$, under age and weight $>6.50$ etc.

\begin{tabular}{|c|c|c|c|}
\hline Sr. No. & Causes & Number of Cases & Percentage \\
\hline 2 & Hypertension & 105 & $78.35 \%$ \\
\hline 6 & Low BP & 21 & $15.57 \%$ \\
\hline 1 & Diabetes Mellitus & 3 & $2.23 \%$ \\
\hline 7 & Kidney Disease & 3 & $2.23 \%$ \\
\hline 3 & Asthma & 1 & $0.74 \%$ \\
\hline 5 & Epilepsy & 1 & $0.74 \%$ \\
\hline \multicolumn{3}{|c|}{ Table 4B. Permanent Deferral } \\
\hline
\end{tabular}

\section{Multiple Responses}

Amongst permanently rejected respondents, hypertension remained the cause in $78.35 \%$ followed by hypotension i.e. $15.57 \%$.

\begin{tabular}{|c|c|c|c|}
\hline Sr. No. & Causes & Male (\%) & Female (\%) \\
\hline 1 & Hypertension & $104(46.43)$ & $1(1.96)$ \\
\hline 5 & Disease & $51(22.77)$ & $1(1.96)$ \\
\hline 2 & Low $\mathrm{Hb}$ & 33 (14.73) & $44(86.27)$ \\
\hline 4 & Medication & $20(8.93)$ & $0(0)$ \\
\hline \multirow[t]{2}{*}{3} & Low BP & $16(7.14)$ & $5(9.8)$ \\
\hline & Total & $224(100)$ & $51(100)$ \\
\hline \multicolumn{4}{|c|}{$\begin{array}{l}\text { Table 5. Distribution of Respondents according to } \\
\text { Leading Five Causes of Deferral }\end{array}$} \\
\hline
\end{tabular}

Among male deferrals, hypertension constituted as a cause in $46.43 \%$ followed by diseases and Anaemia i.e. $22.77 \%$ and $14.73 \%$ respectively. While Anaemia (86.27\%) and hypotension (9.8\%) were the causes of choice in females.

\section{DISCUSSION}

This retrospective descriptive study record based analysis was carried out for whole blood donors at Blood Bank over a 
period of 5 years. Out of 8684 donors, 8304 (95.63\%) were selected and 380 (4.37\%) were rejected. More in females compared with males, i.e. $15.31 \%$ and $3.82 \%$ respectively. However, validation of finding alert caution because of less representation of female donors R. Vasudev(5) (2016) reported incidence of deferral was $7.22 \%$. A total of 343 males were deferred out of 6630 who reported to us for blood donation (5.18\%) and 181 females were deferred out of 623 reporting for donation (29.05\%). The rate of deferral differs from region to region and sometimes in the same region and one centre to another. In this study, the overall deferral rate was about $4.37 \%$ and the deferral rate was about three times higher in females compared with males. The lowest reported rate of rejection was by Talonu $\mathrm{T}^{6}(4 \%)$ in Papua New Guinea ${ }^{7}$ and higher rate $(8 \%$ - 15\%) was reported by Chaudhary,(3) Blumberg(7) and Ranveet.(8) Year wise deferral did not show significant rate differences in present analysis. Deferral rate among females was highest among 18 - 30 years' age group (56.25\%) followed by 31 - 40 years $(23.45 \%)$, while highest deferral rate among males in same brackets were $44.45 \%$ and $25.64 \%$ respectively constituting approximately $2 / 3^{\text {rd }}$ bulk of respondents. Majority of donors (47.16\%) deferred were between 18 - 30 years reported by H. Gajjar et al (2014)(9)- A retrospective study on Blood donor deferral analysis at General Hospital Blood Bank and Dr. Kartikeyan et al(10) (2015), while Dr. Krishna and Dr. Sharada MS et al(1) (2015) reported commonest age group of 18 - 25 years. Rejection of donors was found predominantly on temporary cause criteria, i.e. $64.27 \%$ which can be effectively modified by appropriate interventions comparable with H. Gajjar et al(9) (2014) reporting $81.15 \%$. Temporary deferrals accounted for $97 \%$ in a study by Dr. Kartikeyan et al(10) (2015), while TA Ekwere et al(11) (2016) reported major reasons as permanent (50.4\%) and temporary (39\%) for deferral of donors. The present study revealed almost $1 / 3^{\text {rd }}$, i.e. $31.30 \%$ low haemoglobin level as a cause of temporary rejection and hypertension remained the cause in $78.35 \%$ for permanent deferral. Among male deferrals, hypertension constituted as a cause in $46.43 \%$ followed by diseases and Anaemia i.e. $22.77 \%$ and $14.73 \%$ respectively. While Anaemia (86.27\%) and hypotension $(9.8 \%)$ were the causes of choice in females, H. Gajjar et al(9) (2014) reported the most common reasons were low haemoglobin (48.33\%), high blood pressure (11.94\%), underweight donors (7.95\%) and history of medication use (6.13\%) among total deferral donors. Girish CJ et al(12) (2012) reported the most common cause of deferral was hypertension $(189,39.95 \%)$ followed by anaemia $(92,19.45 \%)$ and low body weight $(43,9.09 \%)$. While A Shah et al(13) (2016) reported the most common reason for deferral was history of jaundice (35.71\%). Other causes were anaemia, high blood pressure and menorrhagia. Dr. Kartikeyan et al(9) (2015) reported most common cause of deferral was low haemoglobin followed by a history of recent illness in male donors. Among females, the most common cause was low haemoglobin accounting for $96 \%$ of the deferrals. Dr. Krishna and Dr. Sharada MS et al(1) (2015) found the most common reasons for deferral were low haemoglobin levels, low body weight, hypertension and alcohol consumption. R Vasudev's(5) (2016) report revealed similar findings with the present study.

\section{CONCLUSION}

This study showed that the deferral rate was $4.37 \%$. Donors are deferred for multiple reasons. The temporary causes of deferral were more as compared to the permanent causes found to be statistically highly significant. Anaemia was the most common reason (31.30\%) in temporary deferrals, while Hypertension (78.35\%) is the most common reason in permanent deferral. Most of these deferral donors, (56.25\%) females and $(44.45 \%)$ males were of age 18 - 30 years old. Among male deferrals, hypertension constituted as a cause in $46.43 \%$ followed by other diseases and Anaemia i.e. $22.77 \%$ and $14.73 \%$ respectively. While Anaemia $(86.27 \%)$ and hypotension $(9.8 \%)$ were the causes of choice in females. Temporary causes for deferral can be easily alleviated by proper nutritious supplement and timely appropriate interventions. The deferral data is not widely recorded and reported to policy makers for transfusion services. If collected and studied in a systematic way, it will definitely improve the collection of blood from prospective blood donors. The blood transfusion services should develop strategies to identify and rationalise the donor selection criteria and be able to decrease unnecessary deferrals.

\section{ACKNOWLEDGEMENTS}

The author thanks the Donors, Technical Staff of Blood Bank, all Teaching Staff of Department of Pathology and Medical Director for constant support in completing this work.

\section{REFERENCES}

[1] Krishna MC, Sharada MS, Harish SG, et al. An analysis of pre-donation deferral of blood donors in a teritiary care teaching hospital blood bank unit, Tumakur, Karnataka, India. International Journal of Healthcare Sciences 2014;2(2):258-62.

[2] Custer B, Chinn A, Hirschler NV, et al. The consequences of temporary deferral on future whole blood donation. Transfusion 2007;47(8):1514-23.

[3] Chaudhary RK, Gupta D, Gupta RK. Analysis of donordeferral pattern in a voluntary blood donor population. Transfusion Med 1995;5(3):209-12.

[4] Bahadur S, Jain S, Goel RK, et al. Analysis of blood donor deferral characteristics in Delhi, India. Southeast Asian J Trop Med Public Health 2009;40(5):1087-91.

[5] Vasudev R, Kaur S, Kumar A, et al. Pre donation deferral a single centre experience. J Blood Disord Transfus 2016;7:356.

[6] Talonu T. Causes of volunteer blood donor rejection in Papua New Guinea. P N G Med J 1983;26(3-4):195-197.

[7] Blumberg N, Shah I, Hoagland J, et al. Evaluation of individuals deferred from blood donation for medical reasons. Vox Sang 1982;42(1):1-7.

[8] Kaur R, Basu S, Marwaha N. A reappraisal of underlying causes in donor deferral. Ann Natl Acad Med Sci 2002;38:93-9.

[9] Gajjar H, Shah FR, Shah NR, et al. Whole blood donor deferral analysis at General hospital blood bank - a retrospective of study. NHL Journal of Medical Science 2014;3(2):72-6.

[10] Karthikeyan TM, Veeramani T, Kumar ACR, et al. Evaluation of pre-donation deferral of young voluntary blood donors in a tertiary rural teaching hospital. Int J of Adv Res 2015;3(7):375-8. 
[11] Ekwere TA, Ino-Ekanem M, Motilewa 00, et al. Pattern of blood donor deferral in a tertiary hospital, Southsouth, Nigeria: a three-year study review. International Journal of Blood transfusion and Immunohematology 2014;4:7-13.

[12] Girish CJ, Chandrashekhar TN, Ramesh BK, et al. Predonation deferral of whole blood donors in district transfusion centre. Journal of Clinical and Diagnostic Research 2012;6(1):47-50.
[13] Shah A, Joshi P, Aghera GB, et al. A study on analysis of blood donation deferral during blood donation camp at tertiary-care teaching hospital in south Gujarat region. Int J Med Sci Public Health 2016;5(5):894-7. 